\title{
Is It Useful to Improve Modelling of Usage Scenarios to Improve the Environmental Footprint of Energy-Using Product?
}

\author{
Charlotte Heslouin, Véronique Perrot-Bernardet, \\ Lionel Pourcheresse and Nicolas Perry
}

\begin{abstract}
When considering the Life Cycle Assessment of an energy-using product, usage is often modelled by average scenarios of use. One challenge of modelling is the availability of data to model the specific scenario in each case. This type of modelling requires the collection of data from several inputs. Also, it can be expensive and time-consuming to collect the specific data to improve the modelling of the use phase. This case study examines a truck refrigeration unit, for which the most environmentally impactful phase is the use phase. The energy consumption of the unit depends on usage. We highlight the importance of modelling a detailed usage scenario specific to each user and examine if it is enough to consider an average usage scenario. This study shows how a specific end-user Life Cycle Assessment and customized recommendation can contribute to improving the global environmental footprint. This is demonstrated by using the energy consumption life cycle inventory analysis of specific end-user behaviour based on experimental data and average scenarios. The results show how far we have to go in the collection of data.
\end{abstract}

\section{Introduction}

Energy-using products are commonly known to have their main environmental impact in the use phase [1-3], hence the importance of accurately modelling the usage of this kind of products.

\footnotetext{
C. Heslouin · L. Pourcheresse

Carrier Transicold Industries, 76520 Franqueville Saint Pierre, France

C. Heslouin · V. Perrot-Bernardet

Arts et Métiers Paristech, Institut de Chambéry, Savoie Technolac,

73375 Le Bourget du Lac, France

e-mail: veronique.perrot-bernardet@ensam.eu

C. Heslouin · N. Perry $(\square)$

Arts et Métiers Paristech, I2M, UMR 5295, 33400 Talence, France

e-mail: nicolas.perry@ensam.eu

(C) The Author(s) 2018

E. Benetto et al. (eds.), Designing Sustainable Technologies,

Products and Policies, https://doi.org/10.1007/978-3-319-66981-6_26
} 
Life Cycle Assessment (LCA) is recognized to be one of the most reliable tools for environmental analysis. LCA is ruled by the ISO 14040 [4] and ISO 14044 [5] standards. LCA methods are described in more detail in the ILCD Handbook [6]. However, none of these references specifically describe how to model the use phase. In fact, the relationship between the usage of product and its environmental performance is rarely considered in LCA. Usually an average usage scenario is used which does not take into account the effects of the usage context on environmental performance, which can be positive or negative. The effect of usage context and its modelling has been recognized as a priority by LCA researchers and practitioners. Telenko and Seepersad [7] proposed to model usage context by using Bayesian network models. Among the usage context factors considered were human (who? skills or habits?), situational (where? when? for what task?) and product (design and specification influencing the use of the product) ones. Ma and Kim [8] proposed a time usage model in which the lifespan of the product was proven to have a strong impact. Egede et al. [9] analyzed the influence of internal and external factors such as vehicle characteristics, location of use and user influence.

In this paper, we consider the case of a LCA of truck refrigeration units (TRUs). It has been shown that TRUs' environmental footprint is mainly due to use of refrigerant and the energy needed during their lifetime [10-12]. However, the use phase it depends on several factors which are influencing the energy consumption. The latter include: trailer specification, size and packaging of product loaded, outside climate (temperature, hygrometry), operating mode (continuous run vs. start/stop), start/stop parameters, type of product (fresh or frozen), type of transport (urban distribution vs. long haul), speed of engine, coefficient of performance (COP) of the unit and refrigerant efficiency [13-18].

In the ecoinvent database V3.2 [19], the fuel consumption of truck refrigeration systems is modelled as an average scenario, assuming a $20 \%$ increase as compared to conventional truck transport without refrigeration [20]. In this scenario, none of the aforementioned parameters that can influence the energy consumption have been taken into consideration.

This paper shows:

- The potential benefits of modelling the usage phase in detail as compared to an average scenario and how the results can be used to provide specific recommendations to end-users that may significantly improve the environmental impact of TRUs.

- The difficulties of collecting reliable and real-time data to perform a LCA of the use phase.

- The kind of data that can be used and how to collect it.

- The potential influence of the use phase life cycle inventory, using an example of a TRU with an average scenario of energy consumption versus different specific scenarios.

- The potential benefits of using specific energy consumption data to improve product design in order to promote sustainable behaviour when using energy-using products. 


\section{Modelling a Product Usage Scenario}

\subsection{Source of Data Collection}

In order to model a usage scenario, it is necessary to gather data from the use phase. Different kinds of data can be collected in order to build usage scenarios. In this paper, four sources of data are identified: real-time data, experimental data, numerical simulation data and average scenario data. They are analysed based on four criteria: (i) time needed to collect data, (ii) cost to collect data, (iii) reliability of data and (iv) accuracy of real usage data (Table 1).

Real-time data are collected directly with the help on sensors while the product is running. It is the most reliable kind of data and allows the analysis of the actual usage specific to each user. However, data collection and analysis can be time-consuming and/or costly, as it is necessary to use multiple sensors and allocate resources to analyse data. In addition, it implies that the environmental footprint must be evaluated continuously or only at the end of the product life. The environmental footprint for a specific set of data will be accurate for a specific usage but rather specific to it, i.e. not necessarily pertinent for another. It can be helpful to build an average scenario, specific to each type of business (e.g. fresh or frozen product, international long haul, national long haul delivery or urban delivery).

Experimental data are collected during punctual measurement on the product in order to recreate real condition of use. Again, collection can be time-consuming and costly, depending on the resources used. However, it requires determining precise parameters to analyze in order to have reliable data. It does allow for analysing the influence of single parameters or for mixing the influence of different parameters. It does allow for creating specific scenarios that can be accurate with real usage.

Data from numerical simulations are based on mathematical routines recreating real-world use conditions. The approach to data collection requires a thorough knowledge of the different parameters to set up the simulation and interpret the results. In some cases, especially with products requiring the integration with another system, it can be difficult to control all the external parameters influencing

Table 1 Proposal of quotation of four sources of data to evaluate the environmental performance of the use phase ${ }^{\mathrm{a}}$

\begin{tabular}{l|l|l|l|l|l}
\hline$\#$ & Solution & $\begin{array}{l}\text { Time } \\
\text { needed }\end{array}$ & Cost & $\begin{array}{l}\text { Reliability of } \\
\text { data }\end{array}$ & $\begin{array}{l}\text { Accuracy of real } \\
\text { usage data }\end{array}$ \\
\hline 1 & Real-time data & -- & - & ++ & ++ \\
\hline 2 & Experimental data & - & - & + & + \\
\hline 3 & $\begin{array}{l}\text { Numerical } \\
\text { simulation data }\end{array}$ & + & + & - & + \\
\hline 4 & $\begin{array}{l}\text { Average scenario } \\
\text { data }\end{array}$ & ++ & ++ & -- & -- \\
\hline
\end{tabular}

${ }^{\mathrm{a}}$ Quotation ++ very good; + good; -bad; -- very bad 
the energy consumption, which can have a detrimental effect on the accuracy of the results. Numerical simulations have the advantage to not to require resources and materials in order to be performed.

Average data are collected from literature reviews, customer statements or expert knowledge. Compared to the previous kinds of data, average data are usually less reliable and, in particular when only a few data are required to build a scenario, can lead to an usage model very far from the actual one. However, this type of data is very easy to gather and at low cost. Average scenario can also be built from the meta-analysis of literature sources or from expert opinions.

\subsection{Data Collected}

In order to identify which data to collect for building usage scenarios for LCA and sensitivity analysis, the important parameters that influence the environmental footprint of the use phase must be identified (such as the technology, the accessories including curtains, partition wall, etc., the setting from the end-user as the setting of the temperature, the operating mode, etc.). These parameters can be further characterized using expert and/or user feedback and/or literature sources. Based on graph theory (which is used to model pairwise relations between parameters), a directed acyclic graph (i.e. a directed graph with no loops or cycles, as e.g. a hierarchy) is built in order to model all the parameters that can influence energy consumption of a TRU (Fig. 1) based on literature review [10-18] and expert knowledges from Carrier Transicold. As explained in the introduction, many

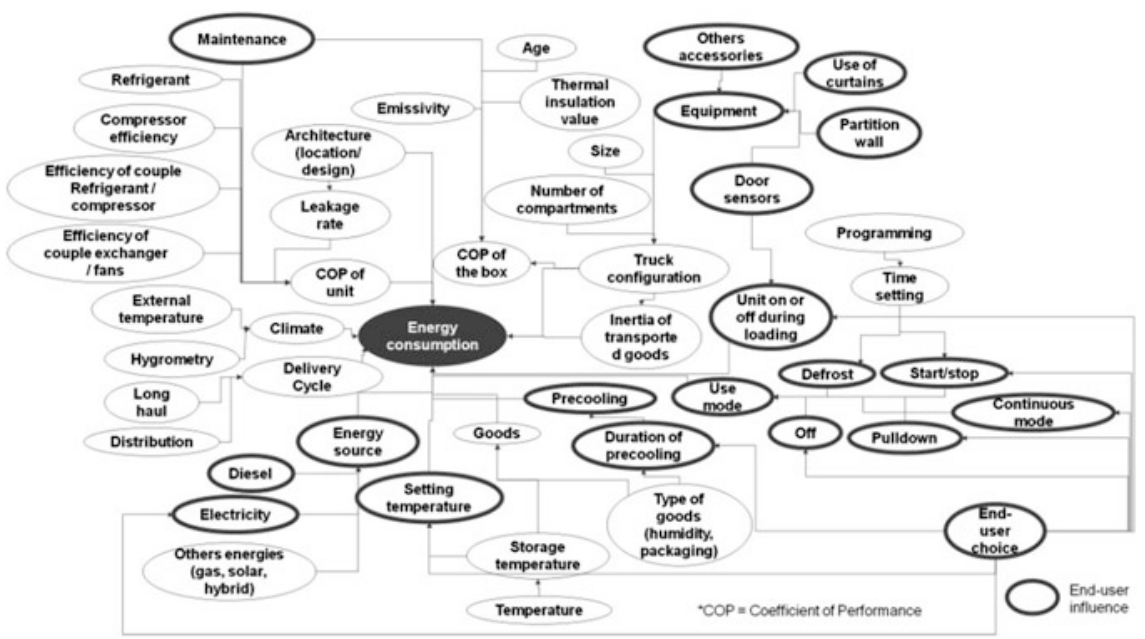

Fig. 1 Directed acyclic graph of energy parameters influencing energy consumption of TRU based on literature review [10-18] and expert knowledge's from Carrier Transicold 
internal and external parameters can influence the energy consumption of the system. The graph shows the complexity of energy consumption modelling and the number of parameters that have to be considered to obtain a realistic usage scenario. As a result, only experimental data with specific parameters were chosen. Many parameters are directly chosen by the customer or the end-user (in this case the driver). Consequently, setting these parameters implies a thorough understanding of end-user behaviours, which can be influenced by different factors (social and personal norms, awareness, habitual processes as routine, intentional processes as willingness for environmental habits and situational influences as surrounding environment) [21]. In this study, we have chosen a few parameters to analyse based on expert knowledge of end-user behaviour and the most commonly used parameters in scientific literature.

\subsection{Scenario Studied}

In order to define the usage scenario, two collection methods were chosen based on the four kinds in Table 1: average scenario data and experimental data.

First a European usage scenario based on average data was modelled and then nine specific scenarios were modelled from experimental measurements using different end-user behaviours and usage settings.

Although it is known that refrigerant leakage [12] significantly contribute to the total environmental impact of the sue phase of TRUs, in this paper we focus only on the influence of energy consumption.

\subsubsection{Average Usage Scenario}

The European average usage scenario was selected. It is a combination of the business activity and one TRU setting:

- Temperature of transportation $\left(0{ }^{\circ} \mathrm{C}\right.$ for fresh product or $-20{ }^{\circ} \mathrm{C}$ for frozen product). This parameter is directly linked to the business activity of the customer.

- Operating mode (start/stop or continuous run). The parameter is chosen by the end-user. It is selected depending on transported product (sensitive or not) but there is no obligation from the manufacturer.

This results in an average scenario of use (Table 2) with an average energy consumption associated of $1 \mathrm{l} / \mathrm{h}$ (this value is defined as a normalized value; it is not the raw value). A weighting factor, obtained from the analysis of $150 \mathrm{TRU}$ usage data sets based on time, has been defined for each combination of parameters and it is indicated here to better illustrate the average European sharing. 
Table 2 Average European usage scenarios of TRUs depending on the main parameters (Carrier Transicold data)

\begin{tabular}{l|l|l}
\hline Operating mode & Temperature of transportation $\left({ }^{\circ} \mathrm{C}\right)$ & Weighting $(\%)$ \\
\hline Continuous run & 0 & 20 \\
\hline Start/stop & 0 & 49 \\
\hline Continuous run & -20 & 0 \\
\hline Start/stop & -20 & 15 \\
\hline Full capacity & 0 or -20 & 16 \\
\hline
\end{tabular}

\subsubsection{Specific Scenarios of Use from Experimental Measures}

The focus here is on the influence of end-user behaviour on the energy consumption. Data for specific use scenarios were collected from experimental measures in external condition, with two similar trailer refrigeration units (in terms of unit model, obsolescence and hours of running), which are actually used by customers. In this case, energy consumption was measured depending on four parameters of use linked to the setting of the TRU (setting point, operating mode) and end-user behaviour (on/off during door openings, use of curtains for door openings). For the setting point, the two most common temperatures $\left(0\right.$ and $\left.-20{ }^{\circ} \mathrm{C}\right)$ were selected from the European average usage scenario and one temperature $\left(-25^{\circ} \mathrm{C}\right)$ was arbitrarily selected to show the influence of a setting temperature that is not optimal but does not affect the cold chain integrity. For each measure, the standard deviation has been calculated. Finally, eleven scenarios of use were built (Table 3). Other possible scenarios are either not representative of a real situation or too resource-expensive considering all the possible combinations of parameters.

\subsection{Results of Energy Consumption Modelling}

In order to assess the potential differences between average and specific usage scenarios, the global energy consumption has been calculated based on $1500 \mathrm{~h}$ of use of a TRU (Fig. 2).

Concerning door-openings, we assumed one 5-min period and one 10-min period during the experimental time of $3 \mathrm{~h}$.

Results show that, depending on the end-user behaviour, energy consumption can increase or decrease compared to the average European scenario. The environmental footprint is directly correlated with diesel energy consumption.

Energy consumption in specific scenarios ranges from -82 to $+9.6 \%$ of the average European scenario when considering $1500 \mathrm{~h}$ of use of the TRU (Fig. 2).

Results also show the influence of different parameters, especially the influence of end-user behaviour. The use of start/stop operating mode for frozen product is a recommended setting to ensure a good quality of cold chain and less energy 
Table 3 Specific scenario from experimental data depending on parameters and energy consumption results (from experimental measures by Carrier Transicold)

\begin{tabular}{l|l|l|l|l|l|l}
\hline$\#$ & $\begin{array}{l}\text { Setting } \\
\text { point }\left({ }^{\circ} \mathrm{C}\right)\end{array}$ & $\begin{array}{l}\text { Operating } \\
\text { mode }\end{array}$ & $\begin{array}{l}\text { On/off } \\
\text { during door } \\
\text { openings }\end{array}$ & $\begin{array}{l}\text { Use of curtains } \\
\text { for door } \\
\text { openings }\end{array}$ & $\begin{array}{l}\text { Energy } \\
\text { consumption } \\
\text { Mean }[1 / \mathrm{h}]\end{array}$ & $\begin{array}{l}\text { Standard } \\
\text { deviation }\end{array}$ \\
\hline 1 & 0 & Continuous & & & 0.58 & 0.09 \\
\hline 2 & 0 & Start/stop & & & 0.18 & 0.06 \\
\hline 3 & 0 & Continuous & On & No & 0.56 & 0.19 \\
\hline 4 & 0 & Continuous & Off & No & 0.55 & 0.11 \\
\hline 5 & 0 & Continuous & Off & Yes & 0.54 & 0.03 \\
\hline 6 & -20 & Start/stop & & & 0.69 & 0.52 \\
\hline 7 & -20 & Continuous & & & 0.78 & 0.18 \\
\hline 8 & -20 & Start/stop & On & No & 0.96 & 0.62 \\
\hline 9 & -20 & Start/stop & Off & No & 0.90 & 0.15 \\
\hline 10 & -20 & Start/stop & Off & Yes & 0.71 & 0.42 \\
\hline 11 & -25 & Start/stop & & & 1.10 & 0.09 \\
\hline
\end{tabular}

${ }^{\mathrm{a}}$ Because of confidentiality reasons, raw energy consumption data cannot be disclosed. Instead we calculated the energy consumption for each scenario as follows: (specific scenario raw energy consumption/European usage scenario raw value)

${ }^{\mathrm{b}}$ Standard deviation is calculated for discrete random variables

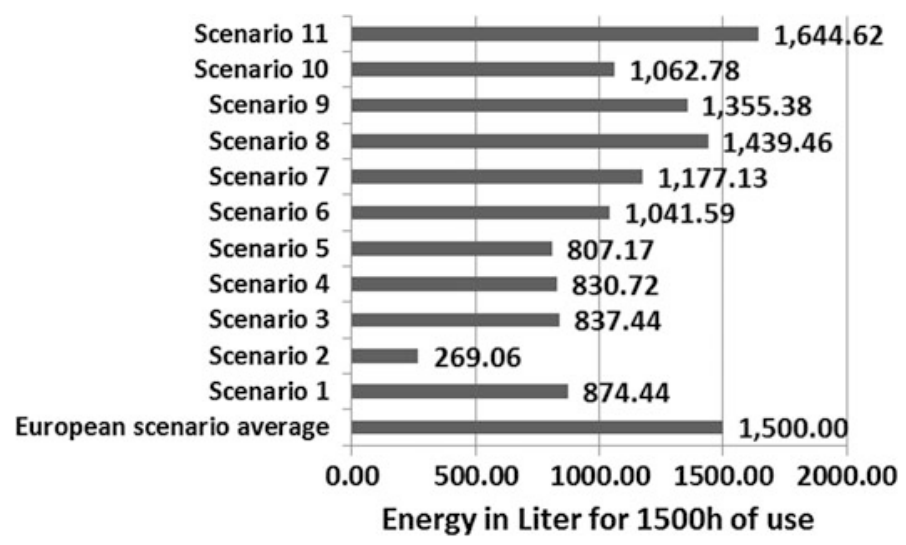

Fig. 2 Energy consumption for $1500 \mathrm{~h}$ of use of the TRU depending on the scenario of use (from experimental data by Carrier Transicold)

consumption. In the European scenario, the use of continuous run for frozen product hardly happens; it can occur if an end-user accidentally sets it or the setting is demanded by a customer. Curtains are optional and they are not always used by end-users. The use (or not) of curtains is not included in the European average scenario. 
Results demonstrate that even when the business of the company strongly influences the scenario of use (e.g. it is not possible to compare fresh products with frozen products), end-users can affect the energy consumption e.g. by setting the temperature (comparison of scenarios 6 and 11). A variation of $36.7 \%$ of energy consumption for a delta of $5{ }^{\circ} \mathrm{C}$ in the setting of the temperature is shown.

When comparing scenario 6 and 7 (influence of operating mode), the energy consumption varies by $11.5 \%$ for $1500 \mathrm{~h}$ of use for frozen products.

When comparing scenario 8 and 9 (TRU turns on or off when doors open) energy consumption varies by $6.2 \%$.

The influence of the use of curtains when doors open (scenario 9 and 10) involves a change of energy consumption of approximately $27.5 \%$.

As a result, the environmental footprint of the use phase can be significantly influenced by the end-user behaviours (setting of the temperature, choice of operating mode, the operation of the TRU when doors are opened and use of accessories such as curtains).

Results also show the importance of taking into consideration the business activity of the customers. The business activity mainly concerned the type of transported products and the type of delivery (long haul transportation or urban delivery with multiple door openings). The business activity will also influence other parameters linked with end-user behaviours. So, the global energy consumption for the whole lifespan of the product and the specific recommendation to end-users will not be the same.

\section{Discussion}

These results highlight how a specific usage scenario can change the lifecycle inventory when considering energy consumption (from +9.6 to $-82 \%$ ). One difficulty in the use of specific energy modelling is to find a good compromise between the need for reliable data and the resources (human, financial, time) that must be allocated to the collection. The difference between the average usage scenario data and the specific usage data is significant.

The study of experimental data took almost two months to be performed due to the size of the system (trailer refrigeration box) and the number of parameters to test. Also, refrigeration measure experimentation had to be conducted over a longer period of time in order to ensure the thermal stabilization of the system. This allowed to check the influence of different parameters on energy consumption in order to provide specific recommendations to the end-user to the aim to guarantee the continuity of the cold chain while reducing energy consumption. Experimental measures can provide as well interesting feedback to engineers for the ecodesign of the units and recommendations to the end-user to enforce sustainable behaviours. It can show the potential benefit of having an innovative design helping to reduce unsustainable end-user behaviours. However, it has to be checked that the 
additional environmental impact generated by the change of design is lower than the avoided impacts allowed during the use phase in order to have a net benefit.

This study finally showed that it is possible to make beneficial specific usage recommendations but the data results are not enough to give specific usage recommendations for each user and their specific usage. In fact, depending on the business of the customer, the recommendations could be adapted. It could be useful to have a specific tool in order to analyse the behaviour of each end-user and to estimate the potential savings by identifying undesirable usage practices. The savings can be estimated based first on experimental data, then on the real data feedback from the end-user. Based on this tool, an "eco-feedback" design strategy to encourage sustainable behaviour can be used. Eco-feedback involves informing the end-users of their energy consumption and associated environmental footprint. This requires real-time data processing analysis and environmental footprint calculation. However, the potential savings of energy consumption and thus the reduction of the environmental footprint (up to $-41.7 \%$ between an optimal and a sub optimal practice of use) can be worth the effort.

\section{Conclusions}

In this study, we compared average fuel consumption, based on the use of a TRU to transport goods, to specific energy consumption, depending on different parameters. The study aimed at showing the influence of energy consumption modelling on the assessment of the environmental performance of the product under study. The hypothesis was that energy consumption modelling based on experimental data provides a greater understanding of the influence of the different parameters useful to model energy consumption.

The results have proven the importance of giving specific usage recommendations to the customer to improve the environmental footprint of TRUs.

It is therefore important to improve the modelling of usage scenarios and of the lifecycle inventory of energy consumption, especially for energy-using products, for which the energy consumption is the major source of environmental impact during the lifespan of the product. However, the gain in using specific scenario modelling must be compared to the additional resources needed to collect data.

\section{References}

1. Brezet $\mathrm{H}$, Van Hamel C, Ecodesign: A promising approach to sustainable production and consumption, Paris: UNEP, 1997.

2. Lockton D, Harrison D, Neville S, Making the user more efficient: Design for sustainable behaviour, International Journal of Sustainable Engineering, Vol. 1, No. 1, 2008, pp. 3-8.

3. Wever R, Van Kujik J, Bock C, User-centred design for sustainable behaviour, Procedia CIRP, Vol. 40, 2016, pp. 469-474. 
4. ISO, Environmental management-Life cycle assessment-Principles and framework, ISO 14040, 2006.

5. ISO, Environmental management -Life cycle assessment - Requirements and guidelines, ISO 14044, 2006.

6. European Commission - Joint Research Centre-Institute for Environment and Sustainability, International Reference Life Cycle Data System (ILCD) Handbook-General guide for life cycle assessment-Detailed guidance, 1st Ed., Luxembourg: Publications Office of the European Union, 2010.

7. Telenko C, Seepersad C.C, Probabilistic graphical modeling of use stage energy consumption: a light vehicle example, Journal of Mechanical Design, Vol. 136, 2014, pp. 1-11.

8. Ma J, Kim H.M, Predictive usage mining for life cycle assessment, Transportation Research Part D, Vol. 38, 2015, pp. 125-143.

9. Egede $\mathrm{P}$ et al, Life cycle assessment of electric vehicles-A framework to consider influencing factors, The 22nd CIRP Conference on Life Cycle Engineering, Sydney, Australia, 2015, Vol. 29, pp. 233-238.

10. Barnabe F, Bensafi A, LCA of a transport refrigeration unit and development of an HVAC\&R equipment ecodesign tool, International congress of Refrigeration, Washington, D.C, 2009.

11. James S J, James C, The food cold-chain and climate change, Food Research International, Vol. 43, 2010, pp 1944-1956.

12. Heslouin C, et al, Effects of product usage scenarios on environmental performance for road transport refrigeration units, 4th International Conference on Sustainability and the Cold Chain, Auckland, 2016.

13. Repice C, Stumpf A, Energy efficiency in transport refrigeration, International Congress of Refrigeration, Beijing, 2007.

14. Tassou S A, De-Lille G, Ge Y.T, Food transport refrigeration-Approaches to reduce energy consumption and environmental impacts of road transport, Applied Thermal Engineering, Vol. 29, 2009, pp 1467-1477.

15. Barnitt R.A, et al, Emissions of transport refrigeration units with CARB Diesel, Gas-to-liquid Diesel, and Emissions Control Devices, SAE Powertrain, Fuels and Lubricants Meeting, San Antonio, Texas, 2009.

16. Cavalier G, Stumpf A, Measurement and simulation of energy consumption of transport refrigerated equipment, 1st Cold Chain Conference, Cambridge, 2010.

17. Fitzgerald W.B et al, Energy use of Integral refrigerated containers in maritime transportation, Energy Policy, Vol. 39, 2011, pp 1885-1896.

18. Wu X, Hu S, Mo S, Carbon footprint model for evaluating the global warming impact of food transport refrigeration systems, Journal of Cleaner Production, Vol. 54, 2013, pp 115-124.

19. <http://www.ecoinvent.org/>, (Accessed 01.03.2017).

20. Levova T, Freight transport with intermodal shipping containers and transport of goods in need of atmosphere control, Zürich, Ecoinvent Center, 2015.

21. Klöckner A.C, Blöbaum A, A comprehensive action determination model: Toward a broader understanding of ecological behavior using the example of travel mode choice, Journal of Environmental Psychology, Vol. 30, 2010, pp 574-586. 
Open Access This chapter is licensed under the terms of the Creative Commons Attribution 4.0 International License (http://creativecommons.org/licenses/by/4.0/), which permits use, sharing, adaptation, distribution and reproduction in any medium or format, as long as you give appropriate credit to the original author(s) and the source, provide a link to the Creative Commons license and indicate if changes were made.

The images or other third party material in this chapter are included in the chapter's Creative Commons license, unless indicated otherwise in a credit line to the material. If material is not included in the chapter's Creative Commons license and your intended use is not permitted by statutory regulation or exceeds the permitted use, you will need to obtain permission directly from the copyright holder.

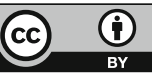

